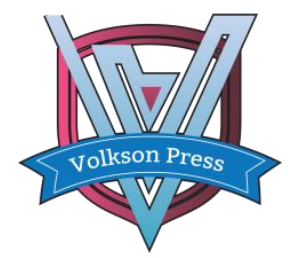

Contents List available at VOLKSON PRESS

Mechanical and Control Engineering (MCE)

DOI : http://doi.org/10.26480/wsmce.01.2017.09.11

\title{
NUMERICAL SIMULATION ON THE MIGRATION BEHAVIOR OF GAS BUBBLES IN THE SIMULATED HIGH TEMPERATURE MELTS
}

\author{
Cao Yifeng, Ma Guojun*, Zhang Xiang \\ Key Laboratory for Ferrous Metallurgy and Resources Utilization of Ministry of Education, Wuhan University of Science and Technology, \\ Hubei Wuhan 430081 \\ *Corresponding Author email: gma@wust.edu.cn
}

This is an open access article distributed under the Creative Commons Attribution License, which permits unrestricted use, distribution, and reproduction in any medium, provided the original work is properly cited

\section{ARTICLE DETAILS}

\section{Article History:}

Received 02 october 2017 Accepted 06 october 2017 Available online 11 november 2017

Keywords:

Electric arc furnace steelmaking, air bubbles, numerical simulation

\section{ABSTRACT}

In the electric arc furnace steelmaking process, about $20 \mathrm{~kg}$ of dust generated per ton steel produced. These dusts are mainly due to the burst of $\mathrm{CO}$ bubbles which generated in the process of decarburization period. In this paper, numerical simulation with Fluent 12.0 are used to study the buoyancy behaviors of single bubble, two bubbles and three bubbles in the simulated high temperature melts in order to provide theoretical basis to reduce dust generation. The results show that the average rise speed of the gas bubble increases with its diameter. When the diameter of gas bubble is smaller, the shape of the bubble keeps more stable, and its ascending trajectory is a straight line. While the diameters of gas bubbles are bigger, it is easier to deform, and the bubble ascending trajectory become unstable. Furthermore, both coalescence and separation of gas bubbles exist when two gas bubbles rise in the simulated high temperature melts. The critical coalescence space of gas bubbles increases with the diameter of gas bubbles.

\section{Introduction}

The Electric arc furnace (EAF), designed for steelmaking from recycled ferrous scrap, co-produces about $20 \mathrm{~kg}$ of dust per ton of steel. The dust contains hazardous and leachable elements such as zinc, lead or cadmium which require EAF dust to be stored in the specific landfills or recycled. Therefore, the management of dust accounts for a significant part of the EAF running costs which is likely to increase in the coming years [1]. The formation of EAF dust proceeds through the vaporization of elements or compounds from the high temperature zones, i.e. arc zone, oxygen blowing zone and the reaction zone during decarburization, the ejection of slag and metal by $\mathrm{CO}$ gas bubbles that burst during decarburization period and the force of the arc, and the direct capturing of charged fines of quartz, lime, fluorite, calcite, nickel metal and graphite in the off-gas during the course of charging $[2,3]$. Of these dust formation mechanisms, the ejection of slag and metal by CO gas bubbles that burst during decarburization period is the major source of EAF dust. Both the velocity of gas bubbles and the coalescence and separation of gas bubbles have significant effects on the dust formation, thus, it is very important to study the behaviour of bubbles in the high temperature melts. In this study, numerical simulation with Fluent 12.0 is used to study the buoyancy behaviour of single bubble, two bubbles and three bubbles in simulated high temperature melts to provide theoretical basis to reduce dust generation in EAF steelmaking process.

\section{NUMERICAL SIMULATION}

The volume of fluid (VOF) model is used in this study. The vertical section size of furnace model is $265 \mathrm{~mm} \times 267 \mathrm{~mm}$, the geometric model and the grid are shown in Figure 1.

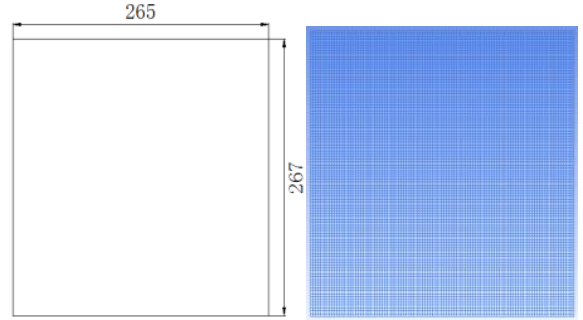

Figure 1: Geometry model and grid of furnace mode

\subsection{Governing equations}

The governing equations for steady, incompressible, immiscible two-fluid VOF model include the continuity, momentum equations, also regardless of the mass transfer and heat transfer, the equations are written as:

$\frac{\partial}{\partial \mathrm{t}}(\rho v)+\nabla(\rho v v)=-\nabla p+\nabla\left[\mu\left(\nabla v+\nabla \boldsymbol{V}^{T}\right)\right]+\rho g+F$

$\nabla v=0$

Where $\rho$ is the fluid density $\left(\mathrm{kg} / \mathrm{m}^{3}\right), v$ is the fluid velocity vector $(\mathrm{m} / \mathrm{s}), p$ is the scalar pressure (Pa), $F$ is a body force vector $\left(\mathrm{N} / \mathrm{m}^{3}\right), g$ is the acceleration vector $\left(\mathrm{m} / \mathrm{s}^{2}\right)$ due to gravity and $\mu$ is the viscosity coefficient (pa·s) $[4,5]$.

\section{Boundary conditions and material parameters}

The initial velocity of bubble is $0.118 \mathrm{~m} / \mathrm{s}$, which is calculated from the gas flow of $50 \mathrm{ml} / \mathrm{min}$. The boundary condition of gas phase is velocity inlet, and the exit is pressure outlet. The no-slip boundary condition is imposed on the ladle wall, the surface tension coefficient is $0.075 \mathrm{n} / \mathrm{m}$. The parameters of the simulated high temperature melts (water) and air are shown in Table 1.

Table 1: Parameters of the numerical simulation

\begin{tabular}{lcc}
\hline Materials & Density $\left(\mathrm{kg} / \mathrm{m}^{3}\right)$ & Viscosity $(\mathrm{kg} / \mathrm{m} \cdot \mathrm{s})$ \\
\hline Water & 998.2 & 0.001003 \\
\hline Air & 1.225 & $1.7894 \times 10^{-5}$ \\
\hline
\end{tabular}

\section{RESULTS AND DISCUSSION}

3.1 Single bubble rising in the simulated high temperature melts

The bubbles are very small in the furnace model, in order to observe the migration behavior of bubbles clearly, the size of the bubbles in the pictures are 2.5 times bigger than the real size. The bubbles rising 
behavior in the simulated high temperature melts are shown in Figure 2. When the diameter of gas bubble is $3 \mathrm{~mm}$, it reaches the surface after 0.9 $\mathrm{s}$, the average speed is $0.283 \mathrm{~m} / \mathrm{s}$. The change of the bubble shape is small, and it almost keeps spherical (Figure 2A). When the gas diameter is $4 \mathrm{~mm}$, the bubble reaches the surface after $0.86 \mathrm{~s}$, the average speed is $0.297 \mathrm{~m} / \mathrm{s}$ (Figure 2B). When the gas diameter is $5 \mathrm{~mm}$, the bubble reaches the surface after $0.85 \mathrm{~s}$, the average speed is $0.3 \mathrm{~m} / \mathrm{s}$. The change of the bubble shape is obvious, and it gradually becomes flat (Figure 2C). When the gas diameter is $6 \mathrm{~mm}$, the bubble reaches the surface after $0.84 \mathrm{~s}$, the average speed is $0.304 \mathrm{~m} / \mathrm{s}$. In the process of bubble rising, the deformation of bubble is very intense, and it rolls up constantly (Figure 2D). The bubble rising time decreases with the increase of initial bubble diameter, and the average velocity increases with the increase of the bubble size (Table 2). Thus, the larger the diameter of the bubble is, the greater the shape changes.
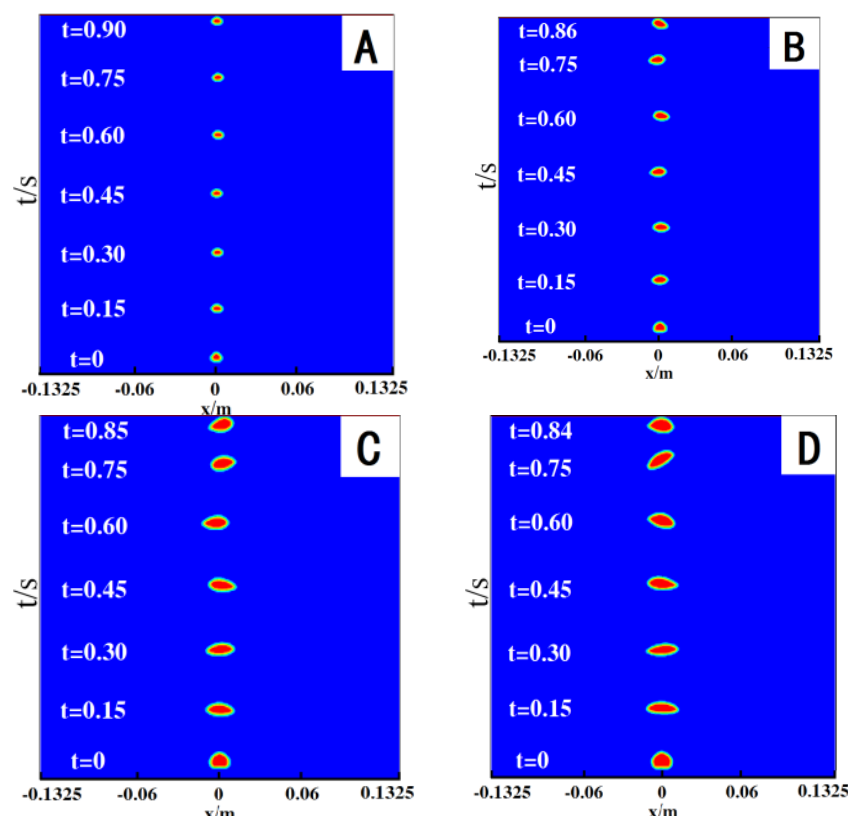

Figure 2: Bubbles rise in the water: (A) $D=3 \mathrm{~mm}$;(B) $D=4 \mathrm{~mm}$;(C) $D=5 \mathrm{~mm}$;(D) $D=6 \mathrm{~mm}$

Table 2: Rising time and average speed in the water

\begin{tabular}{lllll}
\hline Diameter/mm & 3 & 4 & 5 & 6 \\
\hline Rising time/s & 0.9 & 0.86 & 0.85 & 0.84 \\
Average velocity/(m/s) & 0.283 & 0.297 & 0.3 & 0.304 \\
\hline
\end{tabular}

\subsection{Two bubbles rising in the simulated high temperature melts}

Critical merge distance exists while double horizontal bubbles rises in the water, bubbles are hard to coalesce beyond the distance of aperture. Repeated experiments are conducted to confirm the relationship between the critical merge distance and the initial distance of two bubbles (Table $3)$.

Table 3: Parameters of two bubbles in the simulated high temperature melts

\begin{tabular}{ccc}
\hline Diameter $/ \mathrm{mm}$ & Aggregate $/ \mathrm{mm}$ & No aggregate $/ \mathrm{mm}$ \\
\hline 3 & 5.0 & 5.2 \\
4 & 5.8 & 6.0 \\
5 & 6.6 & 6.8 \\
\hline
\end{tabular}

As shown in Figure 3A, the bubbles contact after $0.045 \mathrm{~s}$ when the bubble space is $5.0 \mathrm{~mm}$. The coalesced bubble rises slowly and turns to an oval gradually, then it reaches the surface of melt after $0.884 \mathrm{~s}$. When the bubbles space is $5.2 \mathrm{~mm}$, these two bubbles never contact with each other, they rise gradually and reach the surface of melt after $0.93 \mathrm{~s}$ (Figure 3B). It indicates that the critical merge distance of bubbles is between $5.0 \mathrm{~mm}$ and $5.2 \mathrm{~mm}$ when the diameter of gas bubbles is $3 \mathrm{~mm}$.

When the space of two bubbles is $5.8 \mathrm{~mm}$, they contact after $0.015 \mathrm{~s}$, coalesced bubble rises gradually until it reaches the surface of melts after $0.85 \mathrm{~s}$ (Figure 3C), when the bubbles spacing is $6.0 \mathrm{~mm}$, these two bubbles rise alone without touch until they reach the surface of melts after $0.92 \mathrm{~s}$ (Figure 3D). Thus, the critical merge distance is between $5.8 \mathrm{~mm}$ and 6.0 $\mathrm{mm}$ when the diameter is $4 \mathrm{~mm}$.
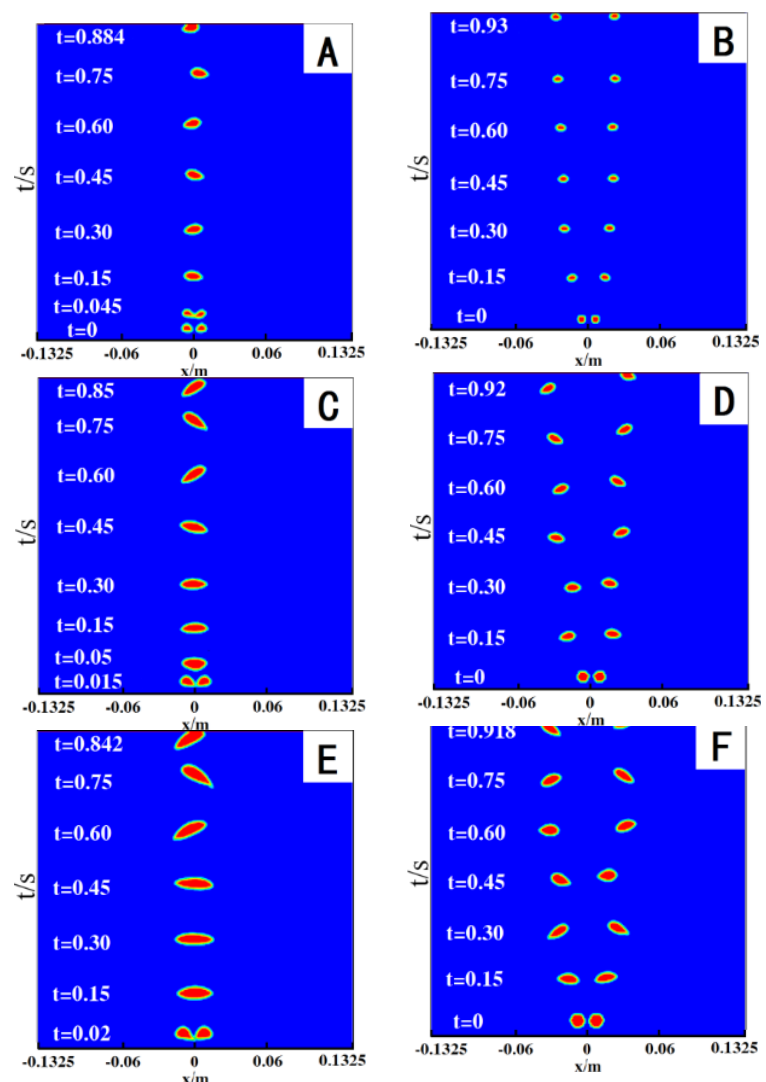

Figure 3: Double bubbles rising behaviors (A) $D=3 \mathrm{~mm}, \mathrm{~s}=5.0 \mathrm{~mm}$;(B) $\mathrm{D}=3 \mathrm{~mm}, \mathrm{~s}=5.2 \mathrm{~mm}$;(C) $\mathrm{D}=4 \mathrm{~mm}, \mathrm{~s}=5.8 \mathrm{~mm}$;(D) $\mathrm{D}=4 \mathrm{~mm}, \mathrm{~s}=6.0 \mathrm{~mm}$;(E) $\mathrm{D}=5 \mathrm{~mm}, \mathrm{~s}=6.6 \mathrm{~mm} ;(\mathrm{F}) \mathrm{D}=5 \mathrm{~mm}, \mathrm{~s}=6.8 \mathrm{~mm}$

When the bubbles spacing is $6.6 \mathrm{~mm}$, the two bubbles contact and merge after $0.02 \mathrm{~s}$. The coalesced bubble rises gradually until it reaches the surface of melts after $0.842 \mathrm{~s}$ (Figure 3E). When the bubbles space is 6.8 $\mathrm{mm}$, these two bubbles never contact until they reach the surface after $0.918 \mathrm{~s}$ (Figure 3F). Thus, the critical fusion distance is between $6.6 \mathrm{~mm}$ and $6.8 \mathrm{~mm}$ when the diameter of gas bubbles is $5 \mathrm{~mm}$.

The simulation results are shown in Table 4. It indicates that the bigger the diameter of the bubbles, the greater of the critical fusion distance. In the process, the shape of the coalesced bubble is concave first and finally becomes a tabular ellipse, and it rolls up constantly.

Table 4. Critical merging distance of different bubbles

\begin{tabular}{llll}
\hline Diameter $/ \mathrm{mm}$ & 3 & 4 & 5 \\
\hline Critical distance $/ \mathrm{mm}$ & $5.0 \sim 5.2$ & $5.8 \sim 6.0$ & $6.6 \sim 6.8$ \\
\hline
\end{tabular}

\subsection{Three bubbles rising in the simulated high temperature melts}

As shown in Figure 4, when the diameters of bubbles are $3 \mathrm{~mm}$, different bubble spaces have different phenomena [6]. While the bubble space is 5.2 $\mathrm{mm}$, these three bubbles get together and become a large one (Figure 4A), when the bubble space is $5.3 \mathrm{~mm}$ and $5.4 \mathrm{~mm}$, these three bubbles never contact, and rise to the surface of melts respectively (Figure 4B, Figure 4C). When the diameters of bubbles are $4 \mathrm{~mm}$, and the space is $6.0 \mathrm{~mm}$, these three bubbles get together to be a large one (Figure 4D), when the space is $6.2 \mathrm{~mm}$, these two bubbles on the left get together, but never contact with the bubble on the right (Figure 4E), when the space is $6.4 \mathrm{~mm}$, these three bubbles rise without contact respectively (Figure $4 \mathrm{~F}$ ).

From these results above, while two bubbles and three bubbles rising in the water under different conditions, both coalescence and separation of gas bubbles exist. In the EAF steelmaking process, As the ejection of slag and metal by $\mathrm{CO}$ gas bubbles that burst during decarburization period is the major source of EAF dust, the CO gas bubbles generated from the decarburization reaction, which typically include nucleation at furnace walls, inclusions or slag droplets and growth inside the melts. The CO- 
bubble size is between 2 and $20 \mathrm{~mm}$ [1]. Guézennec suggested that it would be better to reduce dust formation to control the decarburization reaction in order to decrease the CO-bubble size between 1 and $4 \mathrm{~mm}$.
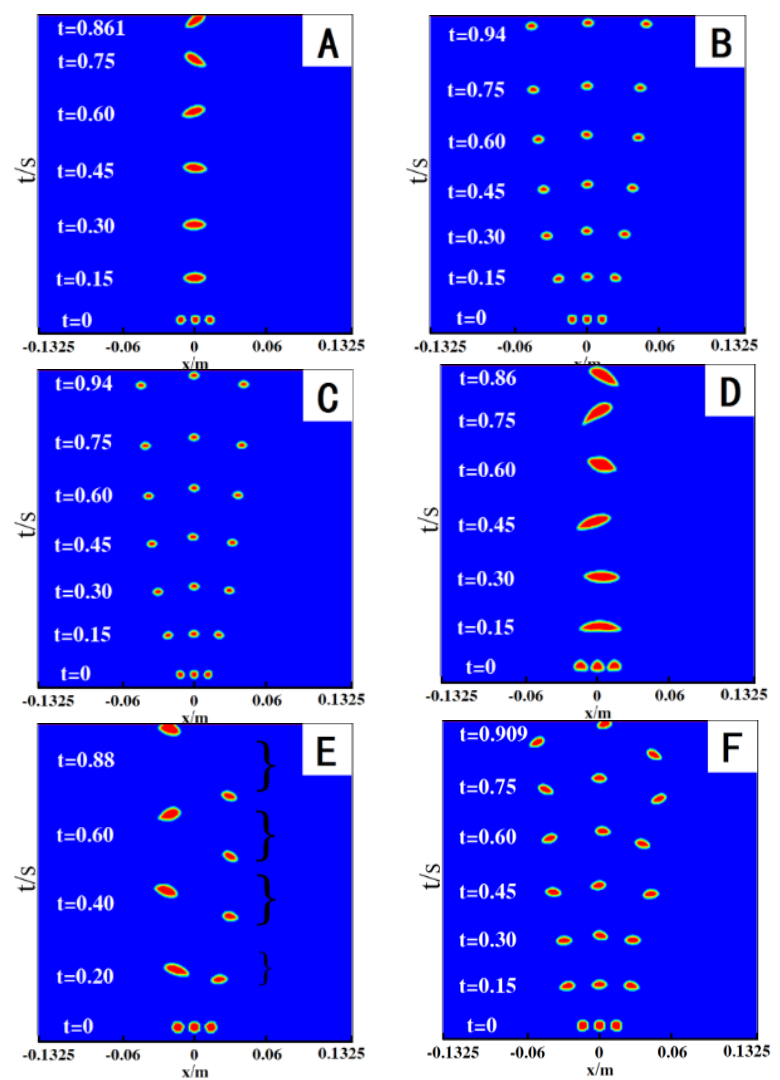

Figure 4: Three bubbles rising behavior: (A) $D=3 \mathrm{~mm}, \mathrm{~s}=5.2 \mathrm{~mm}$;(B) $\mathrm{D}=3 \mathrm{~mm}, \mathrm{~s}=5.3 \mathrm{~mm}$;(C) $\mathrm{D}=3 \mathrm{~mm}, \mathrm{~s}=5.4 \mathrm{~mm}$;(D) $\mathrm{D}=4 \mathrm{~mm}, \mathrm{~s}=6.0 \mathrm{~mm}$;(E) $\mathrm{D}=4 \mathrm{~mm}, \mathrm{~s}=6.2 \mathrm{~mm} ;(\mathrm{F}) \mathrm{D}=4 \mathrm{~mm}, \mathrm{~s}=6.4 \mathrm{~mm}$

\section{CONCLUSIONS}

When the initial diameter of the bubble is bigger in the process of bubble rising, the change of the bubble shape is more obvious. When the initial diameter is $3 \mathrm{~mm}$, it presents a circular. While the initial diameter is $5 \mathrm{~mm}$, it likes a cap. Also, the average velocity increases with the increase of the bubble size, so the bigger the bubble size, the more the dust making. Critical merge distance exists while double horizontal bubbles rise in the water, bubbles are hard to coalesce beyond the critical merge distance. When the initial diameter of the bubble is bigger, the critical merge distance is greater. While two bubbles and three bubbles rise in the simulated high temperature melts, both coalescence and separation of gas bubbles exist.

\section{ACKNOWLEDGMENTS}

The authors gratefully acknowledge the Wuhan Morning Light Plan of Youth Science and Technology (2015070404010206) for financial support.

\section{REFERENCES}

[1] Guézennec, A.G., Huber, J.C., Patisson F., Sessiecq, P., Birat, J.P., Ablitzer, D. 2007. Dust formation by bubble-burst phenomenon at the surface of a liquid steel bath. ISIJ International, 44 (8),1328-1333.

[2] Holappa, L., Han, Z. 2003. Mechanisms of iron entrainment into slag due to rising gas bubbles. ISIJ International, 43 (3), 292-297.

[3] Ma, G., Garbers-Craig A.M. 2006. Cr(VI)-containing EF dusts and filter cake from a stainless-steel waste treatment plant: Part 1-Characteristics and microstructure. Ironmak Steelmak, 33 (3), 229-237.

[4] Zhu, R., Li, Y., Ni, Y. 2010. Numerical simulation of bubble rising in the water. Jiangsu University of Science and Technology, 24 (5), 417-422, 451. Liu, J. 2014. Numerical Simulation on the interaction, coalescence and breakup behaviors of multiple bubbles rising in non-Newtonian fluids. Tianjin University. 